\title{
Anomalous right subclavian artery as cause of dysphagia
}

\author{
Basel Abdelazeem (1) , ${ }^{1}$ Mehak Qureshi, ${ }^{1}$ Saed Alnaimat (1) ${ }^{1,2}$ Rudin Gjeka ${ }^{2}$
}

${ }^{1}$ Internal Medicine Department, McLaren Health Care Corp, Flint, Michigan, USA

${ }^{2}$ Cardiology, McLaren Health Care Corp, Flint, Michigan, USA

\section{Correspondence to}

Dr Basel Abdelazeem;

Basel.Abdelazeem@mclaren.org

Accepted 30 December 2021

\section{DESCRIPTION}

A 59-year-old man with a medical history of hypertension presented to the hospital with chest discomfort with swallowing and a feeling of food 'getting stuck' in his chest on swallowing solids. The patient had dyspnoea on exertion but denied any orthopnoea, dizziness, lower extremity swelling or palpitations. On physical examination, his blood pressure was significantly elevated to $250 / 130 \mathrm{~mm} \mathrm{Hg}$, and breath sounds were slightly diminished bilaterally on auscultation without any wheezing or crackles. On presentation, his troponin I was elevated to $4.65 \mathrm{ng} / \mathrm{L} \quad(0.00-0.06 \mathrm{ng} / \mathrm{L})$, which increased to $32.6 \mathrm{ng} / \mathrm{L}$. ECG did not show any ST-segment or T-wave changes. CT of the neck with contrast showed a non-specific narrowing of the supraglottic airway without any mass or fluid collection and a retro-oesophageal/retrotracheal aberrant right subclavian artery (figure 1). The patient was started on aspirin, ticagrelor, intravenous heparin and atorvastatin. Left coronary angiogram through right radial access showed a proximal occlusion of the left circumflex artery, and a drug-eluting stent was placed. Arteria lusoria accounted for the clinical dysphagia that the patient reported as his oesophagogastroduodenoscopy was found to be negative. This case illustrates the significance of an anomalous retro-oesophageal right subclavian artery resulting in dysphagia symptoms that may be found incidentally on the coronary angiogram.

Anomalous right subclavian artery (ARSA) is also known as arteria lusoria. ${ }^{1}$ It is one of the most common aortic arch anomalies with a prevalence of around $0.5 \%-2.5 \%$ in the general population. ${ }^{1}$ The right subclavian artery originates as the last branch of the aortic arch, travels towards and then down the right arm after crossing the midline of the body commonly, between the oesophagus and vertebral column ( $80 \%$ of cases) and less commonly, between the trachea and oesophagus (15\% of cases). ${ }^{1}$ Most patients remain symptom-free throughout their lifetime, while others can develop symptoms of dysphagia, dyspnoea, coughing, pyrosis, retrosternal pain, acute limb ischaemia and even Horner's syndrome. ${ }^{1-3}$ The clinical manifestations of arteria lusoria result from the compression of the oesophagus by the anteriorly placed right common carotid artery and trachea with the posteriorly coursing right subclavian artery. ${ }^{2}$ In $0.05 \%-0.1 \%$ of the population, dysphagia lusoria can also result from a left subclavian artery in the presence of a rightsided aortic arch and left-sided ligamentous arteriosum, which causes more severe symptoms due to the formation of a true vascular ring that constricts

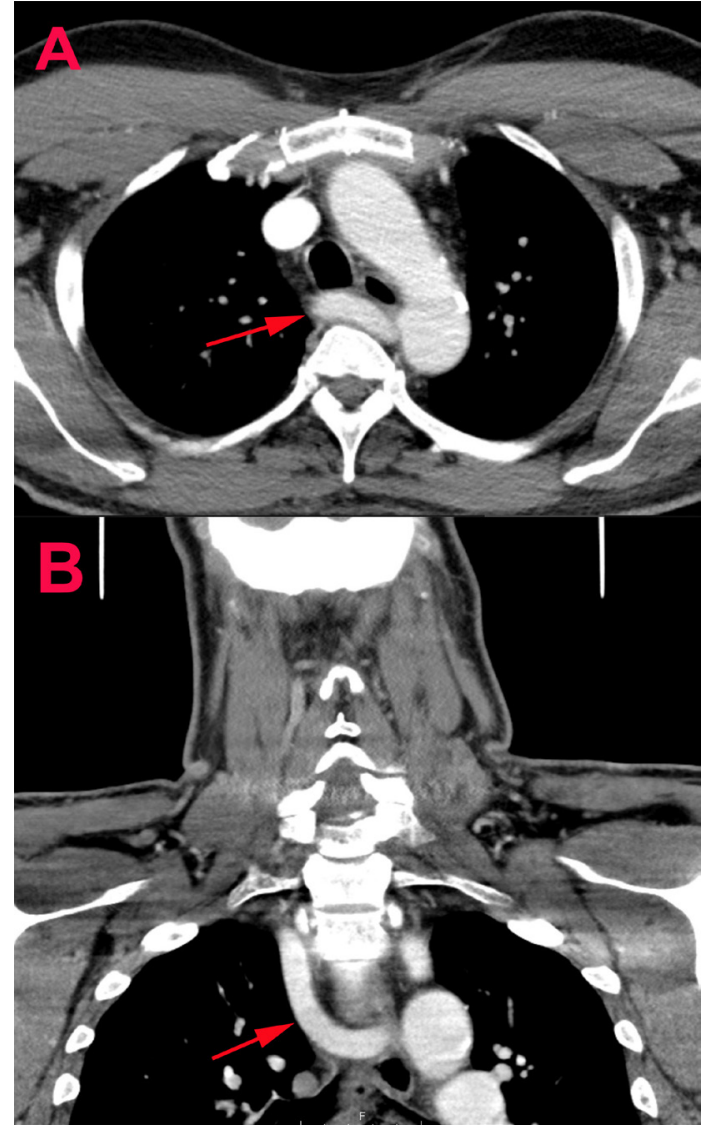

Figure 1 CT neck with contrast illustrating arteria lusoria, an aberrant right subclavian artery (red arrow) originating from the left side of the heart and coursing behind the oesophagus. (A) Axial section; (B) coronal section.

the oesophagus and trachea more significantly compared with the ARSA. ${ }^{3}$ Our patient presented with chest pain secondary to a non-ST segment elevation myocardial infarction and dysphagia, which was secondary to a retro-oesophageal aberrant right subclavian artery. Patients are usually treated symptomatically with proton pump inhibitors, alcohol and smoking cessation, but surgical intervention may be required if symptoms become severe and intractable. ${ }^{3}$

\section{Patient's perspective}

It was very difficult for me to swallow. I didn't expect my blood vessels to narrow my oesophagus and cause me difficulty swallowing; however, I'm glad that my heart is okay. 


\section{Learning points}

- Arteria lusoria, or aberrant right subclavian artery (ARSA), is present in $0.5 \%-2.5 \%$ in the general population and is usually asymptomatic but can present with dysphagia and chest pain. Treatment is usually symptomatic; however, surgical intervention may be needed.

- Cardiologists should be aware of ARSA during right radial cardiac angiogram as it adds technical challenges to the case through its various anatomical variances.
Competing interests None declared.

Patient consent for publication Consent obtained directly from patient(s)

Provenance and peer review Not commissioned; externally peer reviewed.

Case reports provide a valuable learning resource for the scientific community and can indicate areas of interest for future research. They should not be used in isolation to guide treatment choices or public health policy.

\section{ORCID iDs}

Basel Abdelazeem http://orcid.org/0000-0002-2919-6196

Saed Alnaimat http://orcid.org/0000-0003-0450-1462

\section{REFERENCES}

1 Amore D, Casazza D, Casalino A, et al. Symptomatic aberrant right subclavian artery: advantages of a less invasive surgical approach. Ann Thorac Cardiovasc Surg 2020;26:104-7.

2 Ocaya A. Retroesophageal right subclavian artery: a case report and review of the literature. Afr Health Sci 2015;15:1034-7.

3 Coles M, Madray VM, Mareddy C, et al. Dysphagia lusoria: a vascular etiology? JGH Open 2020;4:1238-9.

Copyright 2022 BMJ Publishing Group. All rights reserved. For permission to reuse any of this content visit

https://www.bmj.com/company/products-services/rights-and-licensing/permissions/

BMJ Case Report Fellows may re-use this article for personal use and teaching without any further permission.

Become a Fellow of BMJ Case Reports today and you can:

- Submit as many cases as you like

Enjoy fast sympathetic peer review and rapid publication of accepted articles

- Access all the published articles

- Re-use any of the published material for personal use and teaching without further permission

Customer Service

If you have any further queries about your subscription, please contact our customer services team on +44 (0) 2071111105 or via email at support@bmj.com.

Visit casereports.bmj.com for more articles like this and to become a Fellow 